\title{
Survival Outcomes Among Pancreatic Cancer Patients at Kenyatta National Hospital
}

\section{Faith Moraa}

United States International University

Amsalu Degu ( $\nabla$ amsaludegu@yahoo.com )

United States International University https://orcid.org/0000-0002-6562-0548

\section{Research Article}

Keywords: Survival outcomes, Pancreatic cancer, Kenyatta National Hospital.

Posted Date: August 25th, 2021

DOI: https://doi.org/10.21203/rs.3.rs-829676/v1

License: (c) (i) This work is licensed under a Creative Commons Attribution 4.0 International License. Read Full License 


\section{Abstract}

Purpose: The mortality rate of pancreatic cancer varies throughout the world, with industrialized countries being hard hit. In addition, mortality has risen fast in the past two decades in Kenya and East Africa. However, there was a paucity of conclusive data about the survival of pancreatic cancer patients in the study setting. Hence, this study aimed to assess the survival outcomes of pancreatic cancer patients at Kenyatta National Hospital.

Methods: A hospital-based retrospective cohort analysis was used to evaluate the survival outcomes among pancreatic cancer patients admitted in the study setting between 2015 and 2019. A total of 64 eligible pancreatic cancer patients were included in the study. In the pre-designed data abstraction tool, the data were collected by reviewing the medical records of the patients. The data were entered and analyzed using the Statistical Package for the Social Sciences version 22 software. The mean survival time was estimated using Kaplan Meier survival analysis. Cox regression analysis was employed to estimate the predictors of mortality among pancreatic cancer patients.

Results: The mean age of the study participants was $60.38 \pm 12.61$ years. Most of the patients had adenocarcinoma (96.9\%) and were diagnosed at an advanced stage of the disease. The overall mean and median survival estimate for pancreatic cancer was $48.7 \pm 9.7$ and $39.0 \pm 23.9$ months, respectively. The present study showed that the overall survival rate of pancreatic cancer patients was $79.7 \%$.

Conclusion: The mortality rate of pancreatic cancer in the present was $20 \%$. The overall mean survival estimate for pancreatic cancer was $48.7 \pm 9.7$ months, and the majority had disease progression in the last follow-up period.

\section{Background}

Pancreatic cancer is fast-paced on its mortality index in the world. Globally, the new incidences and deaths are rising parallelly due to the difficulty of early diagnosis (1). According to Global Cancer Incidence, Mortality, and Prevalence (GLOBOCAN) 2018 report, the global mortality index of pancreatic cancer was $4.5 \%$, putting it at position seven worldwide and number twelve for new incidences (2). In terms of prevalence, pancreatic cancer is at position fifteen with its $1.5 \%$ new incidents (2). Even though pancreatic cancer mortality rates are lower than other cancers, such as breast, cervical, lung, or colorectal cancers, it is more dreadful since the new incidences are almost as much as the number of deaths $(3,4)$.

Pancreatic cancers are categorized depending on the cells that give rise to them, giving two main categories; exocrine and neuroendocrine. Exocrine tumors start in cells that produce pancreatic juices, while endocrine tumors affect insulin and other hormone production. Most of the diagnosed cancers are exocrine in nature (5). The event and the progression of carcinoma are caused by the activation of oncogenes, the inactivation of tumor suppressor genes, and the deregulation of the many signaling pathways, among which the EGFR, Akt, and NF-KB pathways appear to be most relevant (6). 
For the longest time, pancreatic cancer has been majorly affecting advanced countries. But in the recent past, pancreatic cancer has been rising in developing countries, too (7). As of 2017, the death rate for pancreatic cancer was $1 \%$ accounting for 667 deaths in total. Although relatively low, this was a marked increase as compared to 188 deaths in 1990. A previous study showed that pancreatic cancer was the leading cause of oncological mortality in European countries (3). The trend can be seen across East Africa, where the disease claimed to kill 36,000 lives between 1990 and 2017(8). In Kenya, the national mortality is at $2.2 \%$, putting pancreatic cancer at number fourteen (9).

Of importance to notice is that mortality and incidence of pancreatic cancer vary throughout the world. High incidence and mortality are more reported in high-income countries, and in recent findings, males are more affected than females (4). Various risk factors are associated with pancreatic cancer, and they vary from region to region in mortality and incidence (7). Pancreatic cancer-related risk factors can be categorized as modifiable and non-modifiable risk factors. Non-modifiable risk factors include an increase in age, diabetes, chronic pancreatitis, and African American race. Notable modifiable risk factors include obesity, smoking, and dietary factors such as non-vegetarians(10).

A previous systematic review reported that pancreatic cancer had a poor prognosis and shorter survival(11). In addition, patients are expected to survive at least five years after diagnosis (12). In an attempt to improve survival rates, early detection is of importance that includes a regular screening of people at risk (10). However, the majority of the studies done on pancreatic cancer survival are in the American and Asian continents, with a dearth of information in the African continent and the study setting. Therefore, the present study was aimed to assess the overall survival of pancreatic cancer patients and its associated factors at the Oncology Department of Kenyatta National Hospital.

\section{Methods}

\section{Study design}

A retrospective cohort study design was employed among pancreatic cancer patients admitted at Kenyatta National Hospital (KNH) between 2015 and 2019.

\section{Study setting and period}

The study was conducted in the Medical record Department of Kenyatta National Hospital. In Kenya's capital city Nairobi, $\mathrm{KNH}$, is situated in the immediate west of Upper Hill. The hospital is situated approximately $3.5 \mathrm{~km}$ west of the main business district of the city. $\mathrm{KNH}$ is the country's largest teaching and referral hospital. $\mathrm{KNH}$ has 50 wards, 22 outpatient clinics, 24 theaters which 16 are specialized, and the Department of Accident and Emergency. Two hundred nine beds for the private wing out of a total bed size of 1800 . 


\section{Target Population}

Patients treated for pancreatic cancer at the Oncology Department of KNH between 2015 and 2019.

\section{Inclusion criteria}

- All adult patients 18 years and older with a confirmed diagnosis of pancreatic cancer admitted to the hospital between 2015 and 2019

- Patients with complete medical records of diagnosis, stage of cancer, and treatment regimen. Documented information about the time interval from the date of primary diagnosis to the date of cancer-related death or last follow-up should be presented.

\section{Exclusion criteria}

- Medical records of patients with incomplete information about the diagnosis, stage of cancer, and treatment regimen were excluded from the study

\section{Sample size determination and sampling techniques}

Consecutive sampling techniques were employed since all eligible pancreatic cancer patients between 2015 and 2019 were studied because of having a small population for this cancer. Hence, a total of 64 pancreatic cancer patients were involved in the study.

\section{Research instruments}

Data abstraction form was the data collection tool used. The data collection tool consisted of sociodemographic information, clinical characteristics of the patients, treatment regimens, and survival outcomes.

\section{Pretesting}

A pretest was conducted in $5 \%$ of the sample population. After that, all the necessary modifications were incorporated into the data collection tool before implementing them in the main study.

\section{Data collection techniques}

The patients' records were obtained from the Health Information Department at Kenyatta National Hospital. A structured data abstraction form was used to review the relevant patient charts. Important information such as the sociodemographic and clinical characteristics of the patient, the type of 
treatment given, and the outcome that resulted from the therapy was included. Time of death and how long the patient survived were taken into consideration. Outcomes were measured in terms of metastasis, mortality, remission, and degree of progression.

\section{Data analysis}

The data collected were analyzed using Statistical Package for the Social Sciences (SPSS), version 22.0. The mean survival time, median survival time, and survival outcomes were analyzed using the KaplanMeier survival analysis. Survival time was determined by calculating the last date of contact minus the first date of a confirmed diagnosis of pancreatic cancer. The time to event analysis was employed to estimate the survival outcome of pancreatic cancer using the Kaplan-Meier survival analysis. Cox regression analysis was employed to estimate the predictors of mortality among pancreatic cancer patients.

\section{Results}

\section{Sociodemographic characteristics of pancreatic cancer patients}

Out of the 64 pancreatic cancer patients involved in the study, 51 were censored, and 13 died. About 34 $(53.1 \%)$ of study participants were females, and 30 (46.9\%) were males. Overall, $45.3 \%$ of the participants were below 60 years old, while $54.7 \%$ were above 60 years of age. The mean age of the study participants was $60.38 \pm 12.61$ years (Table 1 ).

Table 1: Sociodemographic characteristics of pancreatic cancer patients 


\begin{tabular}{|c|c|c|c|}
\hline Variable & Category & Frequency & Percent \\
\hline \multirow[t]{2}{*}{ Age categories } & $<60$ years & 29 & 45.3 \\
\hline & $\geq 60$ years & 35 & 54.7 \\
\hline \multirow[t]{2}{*}{ Gender } & Male & 30 & 46.9 \\
\hline & Female & 34 & 53.1 \\
\hline \multirow[t]{4}{*}{ Marital status } & Single & 3 & 4.65 \\
\hline & Married & 49 & 76.6 \\
\hline & Divorced & 4 & 6.3 \\
\hline & Widowed & 8 & 12.5 \\
\hline \multirow[t]{4}{*}{ Educational level } & Primary & 9 & 14.1 \\
\hline & Secondary & 21 & 32.8 \\
\hline & Tertiary & 27 & 42.2 \\
\hline & Illiterate & 7 & 10.9 \\
\hline \multirow[t]{7}{*}{ Occupational status } & Housewife & 9 & 14.1 \\
\hline & Govt employee & 7 & 10.9 \\
\hline & Retired & 3 & 4.7 \\
\hline & Unemployed & 15 & 23.4 \\
\hline & Farmer & 14 & 21.9 \\
\hline & Daily laborer & 5 & 7.8 \\
\hline & Private employee & 10 & 15.6 \\
\hline \multirow[t]{2}{*}{ Substance use } & Alcohol & 13 & 20.3 \\
\hline & Smoking cigarette & 10 & 15.6 \\
\hline
\end{tabular}

\section{Clinical characteristics of pancreatic patients}

Most of the patient population presented with adenocarcinoma $(62,96.9 \%)$ of those patients, $21 \%$ died. A large percentage of the patients were diagnosed at advanced stages of cancer, with a higher percentage of those diagnosed in stage IV succumbing. It was noted that half of the study cases had other comorbid conditions while the other half didn't have comorbid conditions (Table 2).

Table 2: Clinical characteristics of pancreatic patients 


\begin{tabular}{|c|c|c|c|}
\hline Variable & Category & Frequency & Percent \\
\hline \multirow[t]{3}{*}{ Histological type } & Adenocarcinoma & 62 & 96.9 \\
\hline & Pancreatic neuroendocrine tumors & 1 & 1.6 \\
\hline & Spindle cell carcinoma of the pancreas & 1 & 1.6 \\
\hline \multirow[t]{3}{*}{ Location of cancer } & Head & 49 & 76.6 \\
\hline & Tail & 9 & 14.1 \\
\hline & Body & 6 & 9.4 \\
\hline \multirow[t]{4}{*}{ Stage of cancer } & Stage I & 3 & 4.7 \\
\hline & Stage II & 5 & 7.8 \\
\hline & Stage III & 33 & 51.5 \\
\hline & Stage IV & 23 & 36 \\
\hline \multirow[t]{2}{*}{ Comorbidity } & Present & 32 & 50 \\
\hline & Absent & 32 & 50 \\
\hline \multirow[t]{5}{*}{ Type of comorbidity } & Retroviral disease & 3 & 4.7 \\
\hline & Diabetes mellitus & 17 & 26.6 \\
\hline & Chronic obstructive pulmonary disease & 1 & 1.6 \\
\hline & Deep venous thrombosis & 5 & 7.8 \\
\hline & Hypertension & 14 & 21.9 \\
\hline \multirow[t]{3}{*}{ Number of comorbidities } & Zero & 32 & 50 \\
\hline & One & 24 & 37.5 \\
\hline & Two & 8 & 12.5 \\
\hline
\end{tabular}

Forty-eight percent of the patient population was on palliative care, $31 \%$ of the patients were on chemotherapy (Table 3).

Table 3: Treatment regimens of pancreatic cancer patients 


\begin{tabular}{|lll|}
\hline Variable & Frequency & Percent \\
\hline Treatment regimen & & \\
\hline Chemotherapy & 20 & 31.3 \\
Surgery & 5 & 7.8 \\
Combination therapy & 6 & 9.4 \\
Palliative care & 31 & 48.4 \\
Treatment refusal/missing regimen & 2 & 3.1 \\
\hline Type of chemotherapy regimen & & \\
\hline Doxorubicin -ifosfamide-mesna & 1 & 1.6 \\
Leucovorin+Fluorouracil+Irinotecan+0xaliplatin & 6 & 9.4 \\
Gemcitabine and oxaliplatin & 7 & 10.9 \\
Capecitabine-oxaliplatin & 1 & 1.6 \\
Gemcitabine-Cisplatin & 3 & 4.7 \\
Leucovorin+Fluorouracil+|rinotecan & 3 & 4.7 \\
Cisplatin-Temozolomide & 1 & 1.6 \\
Gemcitabine-capecitabine & 1 & 1.6 \\
Gemcitabine & 1 & 1.6 \\
\hline Number of drugs given & 20 & 31.3 \\
\hline$<5$ & 1 & 1.6 \\
\hline 5-9 & & \\
\hline
\end{tabular}

\section{Survival outcomes of pancreatic cancer patients}

The present study showed that the overall survival rate of pancreatic cancer patients was $79.7 \%$, with a minimal decrease over the five years. The 1-year, 3-year, 5-year survival rates are illustrated in Figure 1.

Seventy-seven percent of the patient population showed disease progression on their last follow-up. Partial remission, complete remission, and non-response were $9 \%, 5 \%$ and $9 \%$, respectively.

The overall mean and median survival estimate for pancreatic cancer was $48.7 \pm 9.7$ months and $39.0 \pm 23.9$ months, respectively. The study found that patients under 60 years old had median survival duration of 67.6 months, whereas those over 60 had a median survival time of 29.2 months. There was a small difference in mean survival time between patients with and without comorbidities. Patients with 
comorbidities had a mean survival time of 38.2 months and those without having a mean survival time of 40 months. Survival was affected by distance metastases, with those without metastasis living an average of 70 months and those with metastasis living an average of 15.4 months. Mean survival was also affected by treatment regimen, with treatment refusal/missing having the shortest survival time. However, none of the indicated variables had statistical significance on mean survival estimates (Table 4).

Table 4: Mean survival estimate among pancreatic cancer patients

\begin{tabular}{|lll|}
\hline Variable & $\begin{array}{l}\text { Mean survival time (months) } \pm \text { standard error } \\
(95 \% \text { Cl) }\end{array}$ & $\begin{array}{l}\text { Log-rank test (p- } \\
\text { value) }\end{array}$ \\
\hline Age (in years) & $67.664 \pm 7.489(52.985-82.342)$ & .163 \\
\hline$\leq 60$ years & $29.185 \pm 4.265(20.825-37.545)$ & \\
\hline Co-morbidity & & .366 \\
\hline Present & $38.200 \pm 11.096(16.452-59.948)$ & \\
\hline Absent & $39.933 \pm 3.747(32.589-47.277)$ & .216 \\
\hline History of substance abuse & & \\
\hline Alcohol & $8.853 \pm 2.618(3.721-13.985)$ & \\
\hline Smoking cigarette & $9.233 \pm 2.095(5.128-13.339)$ & .234 \\
\hline None & $15.42 \pm 4.002(7.576-23.264)$ & \\
\hline Distant metastasis & & .494 \\
\hline No & $70.022 \pm 5.819(58.617-81.428)$ & \\
\hline Yes & $24.867 \pm 4.325(16.389-33.345)$ & \\
\hline Treatment regimen & & $14.706 \pm 4.766(5.365-24.047)$ \\
\hline Chemotherapy & $11.302 \pm 2.534(6.336-16.268)$ & \\
\hline Palliative care & $5 \pm 1(3.04-6.96)$ & \\
\hline Combination therapy & & \\
\hline $\begin{array}{l}\text { Treatment refusal/missing } \\
\text { regimen }\end{array}$ & & \\
\hline
\end{tabular}

\section{Predictors of mortality among pancreatic cancer patients}


The relationship between baseline variables and hazard of mortality was analyzed using Cox proportional hazard regression model. The variables included were age, stage of cancer, distant metastasis, and presence of comorbidity. Variables under treatment regimen were omitted since they were seen to have no direct effect on mortality. Therefore, there was no statistically significant association between the said variables in this study (Table 5).

Table 5: Predictors of mortality among pancreatic cancer patients

\begin{tabular}{|c|c|c|c|c|}
\hline \multirow[t]{2}{*}{ Variable } & \multicolumn{2}{|l|}{ Bivariate Analysis } & \multicolumn{2}{|c|}{ Multivariate Analysis } \\
\hline & $\mathrm{CHR}(95 \% \mathrm{Cl})$ & P-value & $\operatorname{AHR}(95 \% \mathrm{Cl})$ & P-value \\
\hline \multicolumn{5}{|l|}{ Age } \\
\hline$<60$ years & 1 & & 1 & \\
\hline$\geq 60$ years & $0.8(.167-1.586)$ & .173 & $0.8(.731-7.125)$ & .155 \\
\hline \multicolumn{5}{|l|}{ Stage of cancer } \\
\hline Early (I \&II) & 1 & & 1 & \\
\hline Advanced (III \&IV) & $3.2(.000-52.108)$ & .378 & $13.2(.000-52.108)$ & .981 \\
\hline \multicolumn{5}{|l|}{ Distant metastasis } \\
\hline No & 1 & & 1 & \\
\hline Yes & $0.7(.167-1.586)$ & .248 & $0.12(.221-3.554)$ & .866 \\
\hline \multicolumn{5}{|l|}{ Co-morbidity } \\
\hline Present & 1 & & 1 & \\
\hline Absent & $0.3(.723-2.356)$ & .377 & $.122(.550-2.325)$ & .739 \\
\hline
\end{tabular}

Statistically significant $p$-value $<0.05$, CHR: Crude hazard ratio, AHR: Adjusted hazard ratio

\section{Discussion}

This was a retrospective cohort study that aimed to assess the survival rates of patients diagnosed and treated at Kenyatta National hospital and the factors influencing the said survival. A large percent of the patient population (56\%) were diagnosed in the advanced stages of the disease in this study. Among other things that influence the diagnosis of pancreatic cancer, the lack of standardized guidelines internationally for characterization of pancreatic masses and difficulty in early diagnosis are the key reasons (13). Pancreatic cancer has ambiguous signs and symptoms, inadequate screening, and a poor referral system which played a major role in the study setting for late diagnosis. 
This study reported almost similar incidents of pancreatic cancer in both males and females, with females (53.1\%) being slightly more compared to males (46.9\%). A spatial cohort analysis done in Spain reports higher incidence in males, but a very small difference over time was noted between the genders (14). The mean age of pancreatic cancer incidence was found to be around 60 years, with those above 60 years having higher mortality. The study was in agreement with a study done in China where the mean age for the occurrence was 70 years, and advanced age was a poor prognostic factor (13).

Adenocarcinoma (96.9\%) located on the head (76.6\%) of the pancreases was the most common presentation of pancreatic cancer in this study. A study done by Onal et al. reported that $92.8 \%$ patient population with adenocarcinoma (15). Half of the patient population presented with comorbidities, with diabetes mellitus being the most common comorbidity in this patient population (26.6\%). There has been a long-standing relationship between pancreatic cancer and diabetes mellitus, where it can be both a risk factor and presentation of pancreatic cancer (10).

Surgery is the first line in the management of pancreatic cancer, but due to disease progression at the time of diagnosis, only a small percent of the patient population benefits from it(16). This was evident in this study since only $7.8 \%$ of the patients underwent surgery. Combination therapy was seen to have a slightly better mean survival time than the other treatment regimens in our setting. This is in line with findings from Canada, where surgery alone was not an option(17).

The one-year, three-year, and 5-year survival were reported as $81.3 \%, 81.4 \%$, and $79.7 \%$, respectively. This is not in line with the reported statistics from SEER data that report a 5-year survival of $10.8 \%(18)$. Another study done in China reported a 1-year survival rate of $17.8 \%$, a 3-year survival rate of $5.7 \%$, and a 5 -year survival rate of $4.1 \%$ (19) which has a big variance with the current study. The reason for this disparity will probably be linked to the poor documentation of deceased medical records in our setting. The type of treatment regimen is also seen to affect the one-year survival with those patients who underwent resection to have better survival compared to those who had chemoradiation (20). The overall mean survival time was $48.7 \pm 9.7$ months among pancreatic cancer patients, in contrast to another study that reported $12.9 \pm 1.8$ months (15). The data in this study varies due to a very small patient population, incomplete filling of patient files, and missing files hence missing data. From this study, cigarette smoking greatly reduces the mean survival time of pancreatic cancer patients. A previous systematic review and meta-analysis reported that individuals who smoked prediagnosis had an increased mortality rate (21).

\section{Conclusion}

The mortality rate of pancreatic cancer in the present was $20 \%$. The overall mean survival estimate for pancreatic cancer was $48.7 \pm 9.7$ months. Most of the patients had disease progression in the last followup period. The Cox regression analysis showed no statistically significant predictors of mortality among pancreatic cancer patients. 


\section{Declarations}

\section{Funding}

There was no funding to conduct this study.

\section{Conflicts of Interest}

The authors declare that they have no conflicts of interest.

\section{Availability of data and material}

The datasets used and/or analyzed during the current study will be obtained from the corresponding author of this project.

\section{Code availability}

Not applicable

\section{Authors' contributions}

FM and $A D$ were involved from the conception to the final manuscript preparation. All authors reviewed the manuscript.

\section{Ethics Approval}

The actual data collection was conducted after approval from the University of Nairobi/Kenyatta National Hospital Ethics and Research Committee (Approval number: UP7/01/2021). All patient information was treated with the utmost confidentiality. The patients' names were not recorded, and each patient was identified only based on study numbers and their initials. Patient files were not removed from the premises, and the data collected was used for the intended purpose only.

\section{Consent to participate}

Since the study was retrospective study, we have obtained participants informed consent waiver from the Ethics committee.

\section{Consent for publication}

We have obtained approval to publish from the Ethics committee.

\section{Acknowledgments}

The authors would like to acknowledge all the oncology staff members at Kenyatta National Hospital who gave us all the assistance to collect the data in the study. 


\section{References}

1. McGuigan A, Kelly P, Turkington RC, Jones C, Coleman HG, McCain RS. Pancreatic cancer: A review of clinical diagnosis, epidemiology, treatment and outcomes. World J Gastroenterol. 2018;24(43):4846-61.

2. The Global Cancer Observatory. World 2018. Cancer Today. 2020;876:1-2.

3. Ferlay J, Partensky C, Bray F. More deaths from pancreatic cancer than breast cancer in the EU by 2017. Acta Oncol (Madr). 2016;55(9-10):1158-60.

4. Kamisawa T, Wood LD, Itoi T, Takaori K. Pancreatic cancer. Lancet. 2016;388(10039):73-85.

5. Pancreatic Cancer UK. Types of pancreatic cancer fact sheet. 2014;(June 2014):1-9.

6. Malhotra L, Ahn DH, Bloomston M. The Pathogenesis, Diagnosis, and Management of Pancreatic Cancer. J Gastrointest Dig Syst. 2015;05(02):1-11.

7. Pourshams A, Sepanlou SG, Ikuta KS, Bisignano C, Safiri S, Roshandel G, et al. The global, regional, and national burden of pancreatic cancer and its attributable risk factors in 195 countries and territories, 1990-2017: a systematic analysis for the Global Burden of Disease Study 2017. Lancet Gastroenterol Hepatol. 2019;4(12):934-47.

8. Kinuthia K. Pancreatic tumour fastest-growing cause of Kenya's cancer deaths - Business Daily [Internet]. 2019 [cited 2020 Sep 15]. Available from: https://www.businessdailyafrica.com/datahub/Pancreatic-tumour-fastest-growing-cause-ofKenya/3815418-5235456-477lcs/index.html.

9. World Health Organisation IA for R on C. Kenya Source: Globocan 2018. 2020.

10. Midha S, Chawla S, Garg PK. Modifiable and non-modifiable risk factors for pancreatic cancer: A review. Cancer Lett. 2016;381(1):269-77.

11. Carrato A, Falcone A, Ducreux M, Valle JW, Parnaby A, Djazouli K, et al. A Systematic Review of the Burden of Pancreatic Cancer in Europe: Real-World Impact on Survival, Quality of Life and Costs. J Gastrointest Cancer. 2015;46(3):201-11.

12. Rawla P, Sunkara T, Gaduputi V. Epidemiology of Pancreatic Cancer: Global Trends, Etiology and Risk Factors. World J Oncol. 2019;10(1):10-27.

13. Zhang L, Sanagapalli S, Stoita A. Challenges in diagnosis of pancreatic cancer. World J Gastroenterol. 2018;24(19):2047-60.

14. Etxeberria J, Goicoa T, López-Abente G, Riebler A, Ugarte MD. Spatial gender-age-period-cohort analysis of pancreatic cancer mortality in Spain (1990-2013). PLoS One. 2017;12(2).

15. Önal Ö, Yılmaz SD, Eroğlu HN, Eroğlu I, Koçer M. Survival analysis and factors affecting survival in patients with pancreatic cancer. Med Sci Discov. 2020;7(2):412-8.

16. Zeng S, Pöttler M, Lan B, Grützmann R, Pilarsky C, Yang H. Chemoresistance in pancreatic cancer. Int J Mol Sci. 2019;20(18):1-19. 
17. Kanji ZS, Gallinger S. Diagnosis and management of pancreatic cancer. CMAJ. 2013;185(14):121926.

18. Surveillance Epidemiology and End Results Program. Cancer Stat Facts: Pancreatic Cancer. Natl Cancer Inst. 2015;19.

19. Luo J, Xiao L, Wu C, Zheng Y, Zhao N. The Incidence and Survival Rate of Population-Based Pancreatic Cancer Patients: Shanghai Cancer Registry 2004-2009. PLoS One. 2013;8(10):e76052.

20. Kleeff J, Michalski C, Friess H, Büchler MW. Pancreatic cancer: From bench to 5-year survival. Pancreas. 2006;33(2):111-8.

21. Ben QW, Liu J, Sun YW, Wang LF, Zou DW, Yuan YZ. Cigarette smoking and mortality in patients with pancreatic cancer: A systematic review and meta-analysis. Pancreas. 2019;48(8):985-95.

\section{Figures}

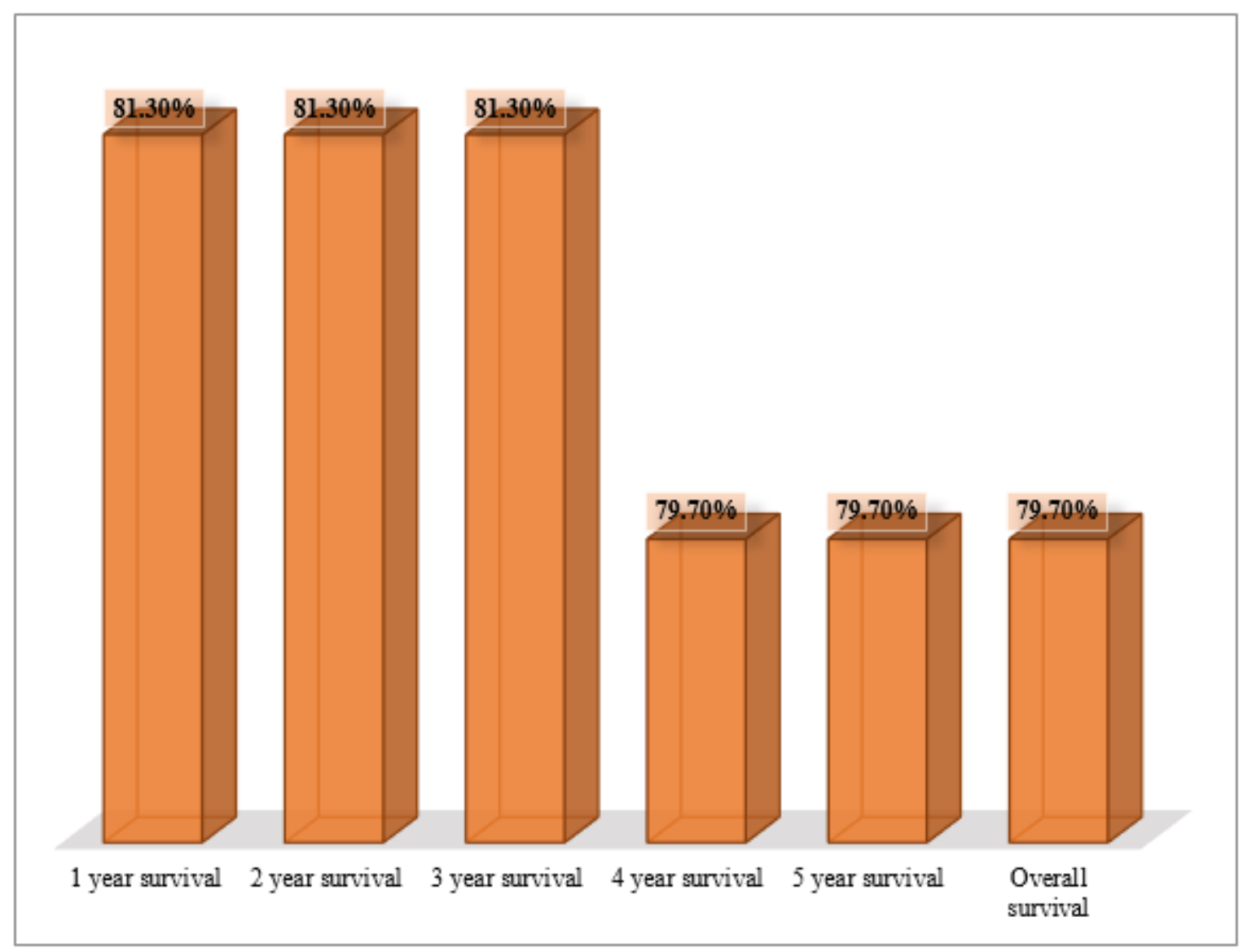

\section{Figure 1}

Survival rates of pancreatic cancer patients. 